\title{
The Impact of e-Health Literacy on Health Promotion Behaviors of High School Students
}

\author{
๑ Kübra Pınar Gürkan1, @ Dijle Ayar² \\ 1Dokuz Eylül University Faculty of Nursing, Department of Public Health Nursing, İzmir, Turkey \\ 2Dokuz Eylül University Faculty of Nursing, Department of Children Health and Diseases Nursing, İzmir, Turkey
}

\begin{abstract}
Aim: The aim of this study was to investigate the effects of e-health literacy on health promotion behaviors on high school students.

Materials and Methods: This descriptive, cross-sectional and relational study was conducted between May-June 2019 in a high school chosen by a random sampling method from the high schools of Narlıdere District of Izmir Province. Data were collected using a descriptive information form, the e-Health Literacy scale in Adolescents and the Adolescent Health Promotion scale. The data collected from the study was analyzed using numbers, percentages, average, Pearson correlation analysis and regression analysis in SPSS 22.0.

Results: $57.1 \%$ of the students included in this study were male and their mean age was $16.52 \pm 0.92$ years. It was found that $47 \%$ of the students were studying in the $10^{\text {th }}$ grade. Of the students' mothers, $42.1 \%$ were primary school graduates, while $29.2 \%$ of the fathers were primary school graduates. It was determined that $95 \%$ of the students used the internet, $69.4 \%$ accessed the internet via mobile phone and $65.3 \%$ did not take health promotion lessons at school. It was also seen that there was a positive moderate relationship between the e-health literacy and mean Health Promotion scale scores of the high school students, and that $17 \%$ of the factors affecting adolescent health promotion behaviors were explained by the total e-health literacy mean scores ( $r=0.416 ; p<0.001)$.

Conclusion: It was found that there was a statistically significant relationship between e-health literacy and the health promotion behaviors of the students, but it was found that the total score means of health promotion behaviors were not at the desired level. Starting from an early period, it is recommended to conduct interventional studies aimed at increasing health promotion behaviors in children and adolescents.

Keywords: Health promotion behaviors, e-health literacy, student
\end{abstract}

\section{Introduction}

The concept of children's health, which is one of the most important indicators of development in a country, lets individuals acquire positive health behaviors through interventions in childhood and youth and lets them help protect their health from many diseases and disabilities risks throughout their lives $(1,2)$. Today's health system is important in terms of adopting practices to protect and improve the health of children. These practices include getting information about health services, making correct and effective decisions about their own health, and taking individual responsibility for their health. Factors such as complex diagnostic processes, constantly evolving and changing technology, cultural differences, limited literacy levels, and age-related physical and cognitive changes may affect children's self-care, self-efficacy, use of services and communication with healthcare teams. In all these processes, the health literacy of individuals stands out as an important factor in seeking and understanding health 
related information and communicating with health information and service providers (3). Researchers found an association between limited health literacy and an increase in the rate of preventable hospital visits and admissions (4).

Health literacy is the sum of the cognitive and social skills related to access, understanding, and use of health information in maintaining and promoting health $(5,6)$. In 2000, "Healthy People 2010" identified the presence of limited health literacy as a public health problem and aimed at setting national goals for its improvement. In 2004, IOM (Institute of Medicine) reported findings that health literacy is critical to improving the health of individuals and the nation (7).

Adolescents maintain the health behaviors and habits they acquire during their adolescent years throughout their life (8). Supporting adolescents' health literacy needs is a crucial step in order for them to adopt a healthy lifestyle in the present and in the future. Also, today's adolescents are known to be prospective, independent health care system users, and young adults who are health literate may contribute to a generation-level reduction of poor health outcomes known to be associated with low health literacy among adults (9). In a study examining the health literacy of adolescents, 200 adolescents were studied in Australia and cigarette and alcohol consumption was found to be higher in adolescents with low health literacy levels (10). In another study which was conducted with 350 adolescents in the USA, it was found that children with low health literacy presented negative behaviors such as carrying weapons and bullying their peers (11). Sharif and Blank (12) reported that, following a child's age, gender and eating habits, a low health literacy level is one of the factors determining Body Mass index.

The development of the concept of e-health literacy has greatly contributed to the field of adolescent health literacy (13). E-health literacy contributes to an adolescent's ability to search, find, understand, evaluate and use health information obtained from electronic sources and use the acquired knowledge to address any health problem (14). Today, the internet is regarded as one of the key and important sources used to access health related information (15). Gray et al. (16) reported that despite the fact that adolescents frequently use information technologies, they experience difficulty in understanding and using online health information. In addition, it has been reported that little is known about the attitudes and perceptional patterns of this group of individuals who use the internet quite frequently concerning their e-health literacy. What's more, it has also been reported that they only feel the need to browse the internet for important health issues and that the consequences of misleading and low quality information on the internet might lead to significant problems $(17,18)$.

The promotion of health literacy at an early age directly affects health literacy in later life as adolescents carry the knowledge and attitudes acquired during this period to adulthood (19). When the literature is examined, no studies examining the effects of e-health literacy on the health promotion behaviors of high school students were found. As a result of this gap in the field, the effect of e-health literacy on health promotion behaviors of high school students was investigated in this study.

\section{Materials and Methods}

This research uses a descriptive, cross-sectional and relational model. This study was conducted with a total of 219 students ranging from 14-18 years of age between May 2019 and June 2019 in a high school chosen by a simple random sampling method among the high schools affiliated to Narlıdere District National Education of Izmir Provincial Directorate of National Education. The sample was determined by a random draw from seven high schools in the Narlıdere region of İzmir, Turkey. Power analysis was performed according to the results of regression analysis. G-Power software was used for power analysis, and the sample size was calculated as 132 students based on the following parameters: a power of $80 \%$ (type II error rate was accepted as 0.20), a confidence interval of 95\% (type I error rate was accepted as 0.05) and an effect size of 0.85 (Özdamar K. Modern Bilimsel Araştırma Yöntemleri, Kaan Kitabevi, Eskişehir, 2003)(20).

\section{Data Collection}

The data of this study were collected by using the descriptive information form, E-health literacy scale in Adolescents and Adolescent Health Promotion scale (AHPS) by using a questionnaire method.

\section{Measures}

\section{Descriptive Information Form}

The descriptive information form is composed of questions about the socio-demographic characteristics of the adolescents such as age, gender, educational status of parents, income status etc.

\section{E-Health Literacy Scale}

This was developed by Norman and Skinner in 2006 to identify traditional literacy, health literacy, information 
retrieval, scientific research, media literacy, and computer literacy (21). This scale consists of two items related to internet use and eight items that measure internet attitude. The Cronbach's alpha value of the original scale was found to be 0.88 . Scale items were determined as follows by a 5 -point Likert-type scaling method: " $1=$ strongly disagree, $2=$ disagree, 3= undecided, 4= agree, 5= strongly agree". The lowest score is 8 and the highest score is 40 . A high score obtained from the scale shows that e-health literacy is high (20). The Cronbach alpha value of the scale, which was adapted by Coşkun and Bebiş (22) was found to be 0.78 . The explained variance ratio of the Turkish scale is $67.54 \%$. The item total score correlation of the scale was found to be between $0.43-0.57$. The Turkish version of the e-health literacy scale in adolescents was determined to be a valid and Reliable scale (22). The Cronbach alpha reliability coefficient was found for the total scale to be 0.78 in this study.

\section{The Adolescent Health Promotion Scale}

This scale was developed by Chen et al. (23) to assess the health promotion behavior level of adolescents. This scale consists of 40 items and six sub-scales. The sub-scales are categorized as nutrition behaviors ( 6 items), social support (7 items), health responsibility ( 8 items), life appreciation (8 items), exercise ( 4 items) and stress management ( 6 items). The scale items are rated in the form of a Likert type scaling as $1=$ never, $2=$ sometimes, $3=$ usually, $4=$ frequently, $5=$ always. The sum of the subscale scores of the sub-scale is obtained by summing the scores of the items, and the total score of the scale is obtained by summing all the subscale scores. The lowest and highest scores that can be obtained from the scale vary between 40 and 200. A high score indicates that health promotion behaviors are positive (23). The validity and reliability studies of the scale were conducted by Temel et al. (24) and Ortabag et al. (25) and it was found that it can be used as a valid and Reliable scale (Cronbach alpha was 0.93 and 0.92 respectively) for the Turkish population in both studies. In this study, the Cronbach alpha reliability coefficient for the total scale was 0.91.

\section{Statistical Analysis}

SPSS 22.0 program was used for statistical analysis of the data. The Shapiro-Wilk Normality test was used to determine if the data complied with a normal distribution. Number, percentage, mean and standard deviation were used as descriptive analysis. The relationship between e-health literacy and health promotion behaviors of students was evaluated by Pearson correlation analysis and the effect of e-health literacy on health promotion behaviors was evaluated by simple regression analysis.

\section{Results}

Of the participants, $57.1 \%$ of the students were male and the mean age of the students was $16.52 \pm 0.92$ years (minimum: 14 ; maximum: 18). It was found that $47 \%$ of the students studied in the $10^{\text {th }}$ grade. Among the participants' parents, $42.1 \%$ of mothers were primary school graduates, while $29.2 \%$ of fathers were high school graduates. It was found that $95 \%$ of them used the internet, $69.4 \%$ accessed the internet via mobile phone and $65.3 \%$ did not take health promotion lessons at school (Table I).

Table I. Socio-demographic characteristics of the participants

The mean score of the high school students participating in the study from the E-health Literacy scale was 28.64 \pm 4.50 . The Health promotion behaviors total score of the students was $127.20 \pm 24.99$. Students were seen to have received the highest mean score from the AHPS Health Responsibility Sub-scale (32.41 \pm 7.49$)$ while the lowest mean score was from the AHPS Nutrition Sub-scale (11.64 \pm 3.78$)$ (Table II).

\section{Table II. Mean and total scale scores of high school students}

When the relationship between the total mean score of the AHPS and the e-health literacy scale of high school students was investigated, it was determined that there was a moderate positive relationship between adolescent health promotion and e-health literacy $(r=0.416 ; p<0.001)$ (Table III).

Table III. The relationship between high school students' adolescent health promotion sub-scales and e-health literacy scale total score means

It was determined that there was a weak positive relationship between adolescent health promotion subscales and e-health literacy ( $r=0.416 ; p<0.001)$ (Table IV).

Table IV. The relationship between high school students' adolescent health promotion scale of subscale and e-health literacy scale total score means

According to simple regression analysis, it was found that there was a positive moderate relationship between e-health literacy and the mean scores of the adolescent health scale $(\beta=0.416, p<0.001)$ in high school students and $17 \%(F=45,353, p<0.001)$ of the factors affecting adolescent 
health promotion behaviors were found to be explained by the mean total scores of e-health literacy.

The regression analysis indicated that e-health literacy explained $17 \%$ of the increase in the adolescent health scale

Table I. Socio-semographic characteristics of the participants

\begin{tabular}{|l|l|l|}
\hline Socio-demographic data & Mean \\
\hline Age & $16.52 \pm .92$ & \multicolumn{2}{l|}{} \\
\hline & n & $\%$ \\
\hline Gender & \multicolumn{2}{|l}{} \\
\hline Female & 94 & 42.9 \\
\hline Male & 125 & 57.1 \\
\hline
\end{tabular}

Class (Grade)

\begin{tabular}{|l|l|l|}
\hline $9^{\text {th }}$ grade & 39 & 17.8 \\
\hline $10^{\text {th }}$ grade & 103 & 47.0 \\
\hline $11^{\text {th }}$ grade & 49 & 22.4 \\
\hline $12^{\text {th }}$ grade & 28 & 12.8 \\
\hline
\end{tabular}

Mother's education level

\begin{tabular}{|l|l|l|}
\hline Not literate & 21 & 9.6 \\
\hline Primary school & 90 & 42.1 \\
\hline Middle School & 56 & 25.6 \\
\hline High school & 44 & 20.1 \\
\hline University & 8 & 3.7 \\
\hline
\end{tabular}

Father's education level

\begin{tabular}{|l|l|l|}
\hline Not literate & 17 & 7.8 \\
\hline Primary school & 64 & 29.2 \\
\hline Middle school & 56 & 25.6 \\
\hline High school & 64 & 29.2 \\
\hline University & 18 & 8.2 \\
\hline
\end{tabular}

\section{Internet use status}

\begin{tabular}{|l|l|l|}
\hline User & 208 & 95.0 \\
\hline Non-user & 11 & 5.0 \\
\hline Internet access way & 58 & 26.5 \\
\hline Computer at home & 7 & 3.2 \\
\hline Computer at school & 152 & 69.4 \\
\hline Mobile phone & 2 & 0.9 \\
\hline Internet cafe & \multicolumn{2}{|l}{} \\
\hline Status of health promotion lesson & 76 & 34.7 \\
\hline Received & 143 & 65.3 \\
\hline Not Received & 219 & 100.0 \\
\hline Total & \multicolumn{2}{|l}{} \\
\hline
\end{tabular}

and increased the adolescent health scale by more than 0.416 ( $\beta=0.416)$ (Table V).

Table V. The effect of e-health literacy of high school students on adolescent health promotion

The regression analysis indicated that e-health literacy explained $9 \%$ of the increase in the health responsibility subscale, $12 \%$ of the increase in the life appreciation subscale, $12 \%$ of the increase in the social support subscale, $7 \%$ of the increase in the nutritional behavior subscale, $1 \%$ of the increase in the exercise subscale and $11 \%$ in the stress management subscale.

Also, e-health literacy increased the health responsibility subscale by more than $0.303(\beta=0.303)$, the life appreciation subscale by more than $0.346(\beta=0.346)$, the social support subscale by more than $0.347(\beta=0.347)$, the nutritional behavior subscale by more than $0.270(\beta=0.270)$, the

Table II. Mean and total scale scores of high school students

\begin{tabular}{|l|l|l|l|}
\hline $\begin{array}{l}\text { Scale total score/sub } \\
\text { dimension scores }\end{array}$ & $\mathbf{X} \pm$ SD & $\begin{array}{l}\text { Min- } \\
\text { max }\end{array}$ & $\begin{array}{l}\text { Number } \\
\text { of X/ } \\
\text { items }\end{array}$ \\
\hline E-health literacy scale & $28.64 \pm 4.50$ & $16-40$ & 3.58 \\
\hline $\begin{array}{l}\text { Adolescent Health Promotion } \\
\text { scale total score }\end{array}$ & $127.20 \pm 4.99$ & $56-190$ & 3.18 \\
\hline $\begin{array}{l}\text { Adolescent Health Promotion } \\
\text { scale health responsibility } \\
\text { sub-dimension }\end{array}$ & $32.41 \pm 7.49$ & $14-50$ & 4.05 \\
\hline $\begin{array}{l}\text { Adolescent Health Promotion } \\
\text { scale self-realization sub } \\
\text { dimension }\end{array}$ & $27.53 \pm 7.33$ & $8-40$ & 3.44 \\
\hline $\begin{array}{l}\text { Adolescent Health Promotion } \\
\text { scale social support sub- } \\
\text { dimension }\end{array}$ & $21.64 \pm 5.73$ & $8-35$ & 3.09 \\
\hline $\begin{array}{l}\text { Adolescent Health Promotion } \\
\text { scale nutrition sub dimension }\end{array}$ & $15.54 \pm 4.10$ & $6-25$ & 2.59 \\
\hline $\begin{array}{l}\text { Adolescent Health Promotion } \\
\text { scale exercise sub-size }\end{array}$ & $11.64 \pm 3.78$ & $4-20$ & 2.91 \\
\hline $\begin{array}{l}\text { Adolescent Health Promotion } \\
\text { scale stress management } \\
\text { sub-dimension }\end{array}$ & $18.41 \pm 5.22$ & $4-30$ & 3.06 \\
\hline SD: Standard deviation, min: Minimum, max: Maximum \\
\hline
\end{tabular}

Table III. The relationship between high school students' adolescent health promotion scale and E-health literacy scale total score means

\begin{tabular}{|l|l|l|}
\hline & $\mathbf{1}$ & $\mathbf{2}$ \\
\hline $\begin{array}{l}\text { 1. Promoting } \\
\text { adolescent health }\end{array}$ & $1.00^{*}$ & - \\
\hline 2. E-health literacy & $0.416^{*}$ & $1.0^{*}$ \\
\hline$*$ * $\mathrm{p}<0.001$ & \\
\hline
\end{tabular}




\begin{tabular}{l} 
Table IV. The relationship between high school students' \\
adolescent health promotion scale of sub-scale and e-health \\
literacy scale total score means \\
\hline
\end{tabular}

Table V. The effect of e-health literacy of high school students on adolescent health promotion

\begin{tabular}{|l|l|}
\hline- & Model 1 \\
\hline- & $\beta$ \\
\hline Adolescent Health Promotion scale & $0.416^{*}$ \\
\hline $\mathbf{R}^{2}$ & 0.17 \\
\hline F & 45,353 \\
\hline P & $<0.001$ \\
\hline${ }^{*}:$ p $<.0001, \beta:$ Beta , $R^{2}:$ Adjusted $\mathrm{R}^{2}$, F: Variance & \\
\hline
\end{tabular}

exercise subscale by more than $0.122(\beta=0.270)$ and the stress management subscale by more than $0.338(\beta=0.270)$ $(p<0.001)$.

\section{Discussion}

As a result of this study conducted to investigate the effect of e-health literacy on the health promotion behaviors of high school students, it was concluded that e-health literacy has an effect on health promotion behaviors. The scores from the e-health literacy scale of the students participating in the study were slightly above the intermediate level with scores of $28.64 \pm 4.50$. Coşkun and Bebiş's (22) study $(27.4 \pm 4.6)$ concurs with the results of this study. By employing the E-health Literacy scale in the American College of Health with 422 students, Britt et al. (26) determined that that the health literacy level of the students was good. In another study conducted with 556 students in Taiwan, E-health Literacy was examined and the students' health literacy level was found to be good (27). In addition, Sukys et al. (28) found that the level of e-health literacy in adolescents was low. It is seen that adolescents use the internet as a source of information about health.

The health promotion behaviors total score of the participants was $127.20 \pm 24.99$ out of 200 . Accordingly, it can be said that adolescents' health promotion behaviors are moderate. Some studies have shown that health promotion behaviors in adolescents are strongly associated with future health outcomes $(29,30)$. When compared with other studies using the same scale, this result remains lower than the results found by Bebiş et al. (31) (132.05 \pm 24.60$)$ and Temel et al. (24) (mean 140.69 \pm 20.10 ) among high school students. Similarly, the total score obtained from the scale was 129 in a study by Chen et al. (23). This situation suggests that students do not receive adequate health education or cannot reflect their education in their behaviors.

It was found that high school students received the highest score from the health responsibility subscale of the AHPS. Temel et al. (24) revealed that $8^{\text {th }}$ grade students $(n=358)$ received the highest score from the health responsibility subscale. In the literature, it was found that adolescents received the highest score from the life appreciation subscale in the AHPS $(22,25,31-33)$. The reason for the difference is thought to be due to the socio-cultural level of the adolescents and their families.

Students received the lowest score from the AHPS in the exercise subscale in our study. Unlike the findings of our study; in some studies, stress management of adolescents $(22,24)$, and in some studies $(33,34)$, the level of health responsibility was found to be the lowest. Similar to the findings in our study, it was found in the literature that there were many studies in which the participants received the lowest scores in the exercise subscale $(25,32,35)$. It was determined that they led a sedentary life watching TV or playing computer games (36). It can be seen that they have difficulty in allocating time to exercise due to having to study for the university entrance exam and that they still cannot adequately perceive the importance of exercise.

It was found that there was a positive moderate relationship between e-health literacy and mean health promotion scale scores of high school students, and that $17 \%$ of the factors affecting adolescent health promotion behaviors were explained by the total e-health literacy mean scores. A systematic review of 17 studies on health literacy and health promotion behaviors of adolescents shows that there is a significant relationship between the health literacy and the health behaviors of adolescents (37). In his study with 1.601 adolescents in 6 different cities of Taiwan, Chang (19) found that adolescents with low health literacy had low health promotion behaviors. In a study conducted in Israel, health literacy skills were not the only determinants of health behavior adoption, although they help access appropriate sources of information which is 
critical to the adoption of health behaviors (38). On the other hand, it was found in a study by Park et al. (39) that high school students with low health literacy had unhealthy diets, and were more likely to be overweight than their peers, and substance abuse was higher among them. In the literature, there is no information about what percentage of health promotion behaviors is accounted for by e-health literacy. However, health promotion behaviors are affected by many factors such as age, gender, family structure and education. Knowing the $17 \%$ effect of e-health literacy on health promotion behaviors is an important result that can contribute to the literature to act as a guide for future interventional studies.

\section{Study Limitation}

Collection of data from only one high school is the limitation of this study.

\section{Conclusion}

As a result of this study, a significant relationship was found between e-health literacy and health promotion behaviors. In this sense, public health nurses, school nurses, and health educators in schools should assess the concept and take the e-health literacy of adolescents into account while designing a health education program. In addition, school nurses should develop their e-health literacy skills to facilitate adolescents' health-promoting activities. There is a need for a systematic approach to the promotion of health literacy and a well-developed curriculum to implement this program. It is recommended that issues related to health promotion should be further integrated into the curriculum or a separate health promotion course should be added. Interventional studies that investigate the relationship between health promotion behaviors and e-health literacy are also recommended.

\section{Ethics}

Ethics Committee Approval: Before starting the study, written permission was obtained from the NonInterventional Research Ethics Committee of Dokuz Eylül University (approval number: 2019/09-28 date: 10.04.2019) and from the institution where the research was conducted. In order to conduct the research, written permission was also obtained from İzmir Provincial Directorate of National Education.

Informed Consent: Written consent was obtained from the parents of the students included in the study. In addition, permission was obtained from the authors who adapted the scales used in this study into Turkish.
Peer-review: Externally and internally peer-reviewed.

\section{Authorship Contributions}

Surgical and Medical Practices: K.P.G., Concept: K.P.G., Design: K.P.G., Data Collection or Processing: K.P.G., D.A., Analysis or Interpretation: K.P.G., D.A., Literature Search: K.P.G., D.A., Writing: K.P.G., D.A.

Conflict of Interest: No conflict of interest was declared by the authors.

Financial Disclosure: The authors have no financial relationships relevant to this article to disclose.

\section{References}

1. Australian Commission On Safety And Quality In Health Care. Consumers, The Health System And Health Literacy. Taking Action To Improve SafetyAnd Quality. Consultation Paper: Sydney; 2013.

2. Birru MS, Monaco VM, Charles L, et al. Internet Usage By LowLiteracy Adults Seeking Health Information: An Observational Analysis. Journal of Medical Internet Research 2004; 6:25-27.

3. Çınar S, Ay A, Boztepe H. Child Health and Health Literacy. Sağlıkta Performans ve Kalite Dergisi 2018; 14:25-39.

4. Ghaddar SF, Valerio MA, Garcia CM, Hansen L. Adolescent health literacy: the importance of credible sources for online health information. Journal of School health 2012; 82:28-36.

5. Berkman ND, Davis TC, McCormack L. Health literacy: what is it? Journal of Health Communication 2010; 15(Suppl 2):9-19.

6. Aras Z, Temel AB. Evaluation of Validity and Reliability of the Turkish Version of Health Literacy Scale. Florence Nightingale Journal of Nursing 2017; 25:85-94

7. Healthy People 2010. Available at: https://www.cdc.gov/nchs/ healthy_people/hp2010.htm

8. Newacheck PW, Wong ST, Galbraith AA, Hung Y. Adolescent health care expenditures: a descriptive profile. Journal of Adolescent Health 2003; 32:3-11.

9. DeWalt DA, Pignone MP. Health literacy and health outcomes:overview of the literature. In: Schwartzberg JG, VanGeest JB,Wang CC (eds). Understanding Health Literacy: Implications forMedicine and Public Health. Chicago: AMA Press 2005; 205-27.

10. Kickbusch I, Pelikan JM, Apfel F, Tsouros A. Health Literacy. WHO Regional Office for Europe: Copenhagen, 2013.

11. Kickbusch I. Health Literacy: Empowering Children to Make Healthy Choices. Virtually Healthy 2006.

12. Sharif I, Blank AE. Relationship between child health literacy and body mass index in overweight children. Patient Education and Counseling 2010; 79:43-8.

13. Kickbusch I, Gordon J, Kropf D, O'Toole L. Learning for WellBeing. A Policy Priority for Children and Youth in Europe. A Process for Change. Paris, Learning for Well-Being Child Health and Health Literacy Consortium of Foundations in Europe 2012; 137-69.

14. Kickbusch IS. Health Literacy: Addressing the Health and Education Divide. Health Promotion International 2001; 16:289-97. 
15. Kirsch I. The International Adult Literacy Survey (IALS): Understanding What Was Measured. Princeton, N): Educational Testing Services 2001; 1-61.

16. Gray NJ, Klein JD, Noyce PR, Sesselberg TS, Cantrill JA. The Internet: a window on adolescent health literacy. Journal of Adolescent Health 2005; 37:243.

17. Skinner H, Biscope S, Poland B. Quality of internet access: barrier behind internet use statistics. Soc Sci Med 2003; 57:87580.

18. Skinner H, Biscope S, Poland B, Goldberg E. How adolescents use technology for health information: implications for health professionals from focus group studies. I Med Internet Res 2003; 5:1-32.

19. Chang LC. Health literacy, self-reported status and health promoting behaviours for adolescents in Taiwan. Journal of Clinical Nursing 2011; 20:190-6.

20. Özdamar K. Modern Scientific Research Methods. Eskişehir, Kaan Publication, 2003

21. Norman C, Skinner HA. eHEALS: the eHealth literacy scale. Journal of Medical Internet Research 2006; 8:27.

22. Coşkun S, Bebiş H. Psychometric evaluation of a Turkısh version of the e-health literacy scale (e-heals) in adolescent. Gulhane Medical Journal 2015; 57:378-84.

23. Chen MY, Wang EK, Yang RJ, Liou YM. Adolescent health promotion scale: development and psychometric testing. Public Health Nursing 2003; 20:104-10.

24. Temel Bayık A, Başalan İz F, Yıldız S, Yetim D. The Reliability and Validity of Adolescent Health Promotion Scale in Turkish Community. Journal of Current Pediatrics 2012; 10:12-22.

25. Ortabag T, Ozdemir S, Bakir B, Tosun N. Health promotion and risk behaviors among adolescents in Turkey. Journal of School Nursing 2011; 27:304-15.

26. Britt RK, Collins W, Wilson K, Linnemeier G, Englebert AE. Health Literacy and Health Behaviors Affecting Modern College Students: A Pilot Study of Issues Identified by the American College Health Association. I Med Internet Res 2017; 19:392.

27. Yang SC, Luo YF, Chiang $\mathrm{CH}$. The Associations Among Individual Factors, e-Health Literacy, and Health-Promoting Lifestyles Among College Students. J Med Internet Res 2017; 19:15.

28. Sukys S, Cesnatiene VI, Ossowsky ZM. Is Health Education at University Associated with Students' Health Literacy? Evidence from Cross Sectional Study Applying HLS-EU-Q. BioMed Research International 2017; 8516843.

29. Kelder SH, Perry CL, Klepp KI, Lytle LL. Longitudinal tracking of adolescent smoking, physical activity and food choice behaviors. American Journal of Public Health 1994; 84:1121-26.

30. Lam TH, Chan BH, Chan SK, Leung GM, Ho SY, Chan WM. A prospective study of stage of change for general health promotion action and health-related lifestyle practices among Chinese adults. Social Science Medicine 2006; 63:1846-56.

31. Bebiş H, Akpunar D, Özdemir S, Kılıç S. Assessment of health promotion behavior of adolescents in a high school. Gulhane Medical Journal 2015; 57:129-35.

32. Dağdeviren Z, Şimşek Z. Health Promotion Behaviors and Related Factors of High School Students in Şanlıurfa. TAF Preventive Medicine Bulletin 2013; 12:135-42.

33. Musavian AS, Pasha A, Rahebi SM, Roushan ZA, Ghanbari A Health promoting behaviors among adolescents: A crosssectional study. Nursing and Midwifery Studies 2014; 3:14560.

34. Karaaslan MM. Çelebioğlu A. Determination of healthy lifestyle behaviors of high school students. Journal of Human Sciences 2018; 15:1355-61.

35. Geçkil E, Dündar Ö. Turkish adolescent health risk behaviors and self-esteem. Social Behavior and Personality 2011; 39:219-28.

36. Aghamolaei T, Tavafian SS. Health Behaviors of a Sample of Adolescents in Bandar Abbas, Iran. Int J High Risk Behav Addict 2013; 2:34-8

37. Fleary SA, Joseph P, Pappagianopoulos JE. Adolescent health literacy and health behaviors: a systematic review. Journal of Adolescence 2018; 62:116-27.

38. Levin-Zamir D, Baron-Epel OB, Cohen V, Elhayany A The association of health literacy with health behavior, socioeconomic indicators, and self-assessed health from a national adult survey in Israel. Journal of Health Communication 2016; 21:61-8.

39. Park A, Eckert TL, Zaso MJ, et al. Associations between health literacy and health behaviors among urban high school students. Journal of School Health 2017; 87:885-93. 